\title{
Observed Interannual Variability of the Florida Current: Wind Forcing and the North Atlantic Oscillation
}

\author{
Pedro N. DiNezio And Lewis J. Gramer \\ Cooperative Institute for Marine and Atmospheric Studies, Rosenstiel School of Marine and Atmospheric Science, \\ University of Miami, Miami, Florida \\ WILLIAM E. JOHNS \\ Rosenstiel School of Marine and Atmospheric Science, University of Miami, Miami, Florida \\ CHRistopher S. Meinen AND MOLly O. BARINGer \\ Physical Oceanography Division, NOAA/Atlantic Oceanographic and Meteorological Laboratory, Miami, Florida
}

(Manuscript received 14 February 2008, in final form 5 September 2008)

\begin{abstract}
The role of wind stress curl (WSC) forcing in the observed interannual variability of the Florida Current (FC) transport is investigated. Evidence is provided for baroclinic adjustment as a physical mechanism linking interannual changes in WSC forcing and changes in the circulation of the North Atlantic subtropical gyre. A continuous monthly time series of FC transport is constructed using daily transports estimated from undersea telephone cables near $27^{\circ} \mathrm{N}$ in the Straits of Florida. This 25-yr-long time series is linearly regressed against interannual WSC variability derived from the NCEP-NCAR reanalysis. The results indicate that a substantial fraction of the FC transport variability at 3-12-yr periods is explained by low-frequency WSC variations. A lagged regression analysis is performed to explore hypothetical adjustment times of the winddriven circulation. The estimated lag times are at least 2 times faster than those predicted by linear beta-plane planetary wave theory. Possible reasons for this discrepancy are discussed within the context of recent observational and theoretical developments. The results are then linked with earlier findings of a lowfrequency anticorrelation between FC transport and the North Atlantic Oscillation (NAO) index, showing that this relationship could result from the positive (negative) WSC anomalies that develop between $20^{\circ}$ and $30^{\circ} \mathrm{N}$ in the western North Atlantic during high (low) NAO phases. Ultimately, the observed role of wind forcing on the interannual variability of the FC could represent a benchmark for current efforts to monitor and predict the North Atlantic circulation.
\end{abstract}

\section{Introduction}

The Florida Current (FC), the name commonly used for the Gulf Stream where it flows through the Straits of Florida, is a component of the western boundary current system of the North Atlantic subtropical gyre. In addition to being a component of the wind-driven gyre, it is also a pathway for the warm-water return flow of the global meridional overturning circulation (MOC). Over the past $25 \mathrm{yr}$, electromagnetically induced voltages on

Corresponding author address: Pedro N. DiNezio, CIMAS, RSMAS, University of Miami, 4600 Rickenbacker Causeway, Miami, FL 33149.

E-mail: pdinezio@rsmas.miami.edu several undersea telephone cables near $27^{\circ} \mathrm{N}$ have been successfully used to produce daily estimates of the total volume transport of seawater through the Straits of Florida (Larsen and Sanford 1985; Baringer and Larsen 2001).

This cable record has been used to study seasonal variations in FC transport along with sea level differences and direct ocean current measurements (Schott and Zantopp 1985; Molinari et al. 1985; Lee et al. 1985; Larsen and Sanford 1985; Baringer and Larsen 2001; Hamilton et al. 2005). The relationship between these seasonal changes and variations in wind forcing over the North Atlantic has been extensively studied (Schott and Zantopp 1985; Lee et al. 1985; Lee and Williams 1988). Most observational studies agree with the model results 
of Anderson and Corry (1985a,b), Fanning et al. (1994), and Greatbatch et al. (1995), identifying local and remote along-isobath wind stress forcing as a driving mechanism for annual and higher-frequency variability, while modeling studies by Böning et al. (1991) point to wind stress curl (WSC) variability over the western North Atlantic.

Significant interannual variability has also been inferred from sea level differences (Schott and Zantopp 1985) and from the cable-derived transport estimates (Baringer and Larsen 2001). Using 16 years of data, Baringer and Larsen report peak-to-peak interannual variations of $2-3 \mathrm{~Sv}\left(1 \mathrm{~Sv} \equiv 10^{6} \mathrm{~m}^{3} \mathrm{~s}^{-1}\right)$ having periods between 2 and $3 \mathrm{yr}$ and an apparent longer decadalperiod variation of $\pm 2 \mathrm{~Sv}$. The interannual estimate agrees with those previously derived by Schott and Zantopp for the same frequency band, using approximately $8 \mathrm{yr}$ of sea level differences between Bimini and Miami.

Suggestion has been made in the literature of a relationship between variations in FC transport and interannual and longer-period atmospheric signals. Baringer and Larsen (2001) compared a 2-yr running mean of FC cable transport with variations in the North Atlantic Oscillation (NAO) index over the period 1982-96. Although their analysis spanned fewer than two complete cycles of a 10-12-yr mode, also present in the lowfrequency variability of both the FC and the NAO, they did identify a strong anticorrelation between the two signals at shorter interannual periods. The NAO index is a measure of broad atmospheric variability over the North Atlantic, based on differences in sea level atmospheric pressure at long-term monitoring stations in Iceland and the Azores (Hurrell and van Loon 1997). Changes in the NAO index are associated with changes in the strength of the westerly winds over the North Atlantic, with a high NAO corresponding to stronger westerlies and enhanced negative WSC over the midlatitude North Atlantic. Baringer and Larsen found a lag of 18 months between anomalies in the NAO index and FC transport anomalies of opposite sign, but the physical mechanism for this observed relationship has not heretofore been established.

On interannual time scales, theoretical (Anderson and Gill 1975) and model studies (Anderson et al. 1979) indicate that adjustment of the North Atlantic subtropical gyre to changes in atmospheric forcing over the basin is achieved by the propagation of long-limit (nondispersive) barotropic and baroclinic Rossby waves adjusting the Sverdrup circulation in their wake. Ultimately, only the baroclinic Rossby waves could transmit this signal to the Straits of Florida through the topography of the Bahamas. This assumption is supported by studies using quasigeostrophic two-layer models (e.g.,
Pedlosky and Spall 1999; Pedlosky 2000) showing that westward-propagating energy associated with baroclinic Rossby waves can be radiated westward by small gaps in a topographic barrier, thus making this idealized island arc transparent to the waves. While the spinup theory of Anderson and Gill (1975) focused on first-mode baroclinic Rossby waves excited by WSC forcing along the eastern boundary, subsequent studies using numerical models have shown that free Rossby waves can also be generated in the ocean interior by wind forcing, for example, over an ocean ridge (Barnier 1988), or they can be directly forced by the wind over open ocean (White 1977; White et al. 1998; Qiu et al. 1997). These results are consistent with recent satellite altimeter observations indicating significant generation of both barotropic and baroclinic Rossby waves in the ocean interior, sometimes correlated with major topographic features (Chelton and Schlax 1996, hereafter CS96).

The present study analyzes monthly mean WSC data over the $27^{\circ} \mathrm{N}$ latitude band across the subtropical North Atlantic to show a relationship between WSC and FC transport variability with periods in the range between 2 and 12 years, the longest time scale that can be studied with the cable data available to date. It is demonstrated that FC fluctuations on these time scales are consistent with a lagged adjustment of the subtropical gyre to interior WSC anomalies associated with the NAO. While such a relationship is not unexpected, our analysis shows that the connection between the FC and the NAO is a rather subtle one, in which WSC anomalies near $20^{\circ}$ $30^{\circ} \mathrm{N}$ that are opposite in sign to those in the main center of action of the NAO could actually be driving the response. The analysis further suggests that the response time of the gyre to these WSC anomalies is significantly faster than predicted by conventional planetary wave theory but consistent with recent observations and theoretical developments.

The paper is organized as follows. First, we describe the FC cable transport time series and procedures used for gap filling and filtering. Next, we analyze the National Centers for Environmental Prediction-National Center for Atmospheric Research (NCEP-NCAR) reanalysis wind stress data over the North Atlantic for 1982-2007, illustrating the WSC pattern associated with the NAO focusing on the zonal band of the cable measurements $\left(24^{\circ}-29^{\circ} \mathrm{N}\right)$. Sverdrup transport signals originating in the western, central, and eastern parts of the gyre are identified. Then, wavelet and lagged regression analyses are performed to explore the relationship of these forcing anomalies to the FC transport. Finally, we conclude with a discussion of the observed coherences with regard to Sverdrup balance and adjustment times. 


\section{Data and methods}

\section{a. Florida Current transport time series}

Using a methodology outlined by Stommel (Stommel 1948) and successfully implemented by Sanford and Larsen (Sanford 1982; Larsen and Sanford 1985; Mayer and Larsen 1986; Larsen 1992), several telephone cables lying beneath the sea floor have been used to estimate the transport of seawater through the Straits of Florida. Our study uses approximately $25 \mathrm{yr}$ of daily estimates of volume transport derived from voltages recorded on a series of cables near $27^{\circ} \mathrm{N}$ (available online at www.aoml.noaa.gov/phod/floridacurrent) to construct a monthly FC transport time series (Fig. 1a). Over the past $25 \mathrm{yr}$, the in situ transport observations have been variously computed from velocity sections collected from acoustic Pegasus velocity profilers (Mayer and Larsen 1986) and later using a simpler free-falling dropsonde (Richardson and Schmitz 1965; C. Meinen, M. O. Baringer, and R. F. Garcia 2008, unpublished manuscript). The root-mean-square (RMS) difference between concurrent daily estimates is less than $3 \mathrm{~Sv}$. The resulting cable time series contains occasional gaps in the record as a result of instrument failures and funding vagaries; the largest gap occurred between 1998 and 2000, when funding for the project was cut at the same time the recoding equipment needed to be removed while the cable was decommissioned. The second longest gap occurred in September to October 2004 when Hurricanes Frances and Jeanne destroyed the building in which the recording system was housed.

Our analysis herein is based on monthly means computed for months with at least 15 days of daily data. Owing to the high-frequency (short integral time scale) nature of the dominant variability, the estimated uncertainty of the monthly mean estimates is on the order of $1 \mathrm{~Sv}$. After this procedure, eleven 1-3-month gaps remain, along with a single 20-month gap in 1998-2000. To analyze the full period between 1982 and 2007, the following methodology is used to fill each gap depending on its length in months. All gaps of 3-months duration or fewer are linearly interpolated. The remaining 20 -month gap is then reconstructed using a climatological annual cycle calculated based on the 1983-2006 record, with a linear trend added to match the data in the years immediately before and after the gap. During the 20-month gap, 11 daily snapshots of transport estimates were obtained by the Florida Current Project using dropsonde casts with a mean transport of $30.7 \mathrm{~Sv}$, and a standard deviation of 3.0 Sv. Moreover, satellitederived interannual anomalies of the sea level difference across the Straits of Florida-a proxy for geo- strophic transport-show the two large cycles during the 1990s and 2000s, with a smooth transition from the 1998 high to the 2000 low (G. Goni 2008, personal communication). These two independent sets of observations support the interpolation of the gap using a linear trend solely to produce a continuous signal for filtering.

Prior to any filtering or statistical analyses, the mean 1982-2007 transport of $32 \mathrm{~Sv}$ is removed from the fully reconstructed monthly time series. Interannual variations are then examined using bandpass filters in both the 2-12-yr before present (YBP) and 3-12-yr (3-12 YBP) bands (Fig. 1b) to allow us to test the sensitivity of the results to the filter period. Throughout this study, fifth-order Butterworth bandpass filters are applied with no phase shifting in the time domain (We elect to use period rather than frequency throughout the paper to clarify for the reader the time intervals being discussed). Spurious edge effects are avoided by removing half of the low-pass period at both ends of the filtered time series. For reasons to be discussed later, the 3-12 YBP filtered series is the one we will focus on in comparisons with the WSC signals.

It should be noted that several other techniques for completing the monthly FC transport record were evaluated in this study, including simple linear interpolation of all gaps, or filling the 20-month gap using climatological annual cycles corresponding to other subsections of the cable record. However, after bandpass filtering, the FC transport time series resulting from the different gap-filling methodologies are found to be indistinguishable (figure not shown). Data from the 20-month gap are excluded from all statistical relationships stated in this paper. Thus, the main results presented in this paper are insensitive to the specific method used to fill the gaps in the FC transport time series.

\section{b. Wind stress and WSC}

Surface wind stress fields from the NCEP-NCAR reanalysis project (Kalnay et al. 1996) are used to explore the role of wind forcing in the interannual variability of the FC. Monthly mean estimates of the zonal $\left(\tau^{x}\right)$ and meridional $\left(\tau^{y}\right)$ wind stress on a T62 Gaussian grid (approximately $2^{\circ} \times 2^{\circ}$ resolution) are used to estimate the vertical component of the curl of the surface wind stress, $(\nabla \times \boldsymbol{\tau})^{z}$, hereinafter WSC. The 1982-2007 mean climatological WSC (Fig. 2) shows a region of negative values over most of the subtropical North Atlantic, which contributes to the long-term mean of the wind-driven component of the FC through linear vorticity dynamics (i.e., Sverdrup balance). This mean WSC produces a Sverdrup transport of approximately $18 \mathrm{~Sv}$ at $27^{\circ} \mathrm{N}$. Using water mass analysis, Schmitz and Richardson (1991) 


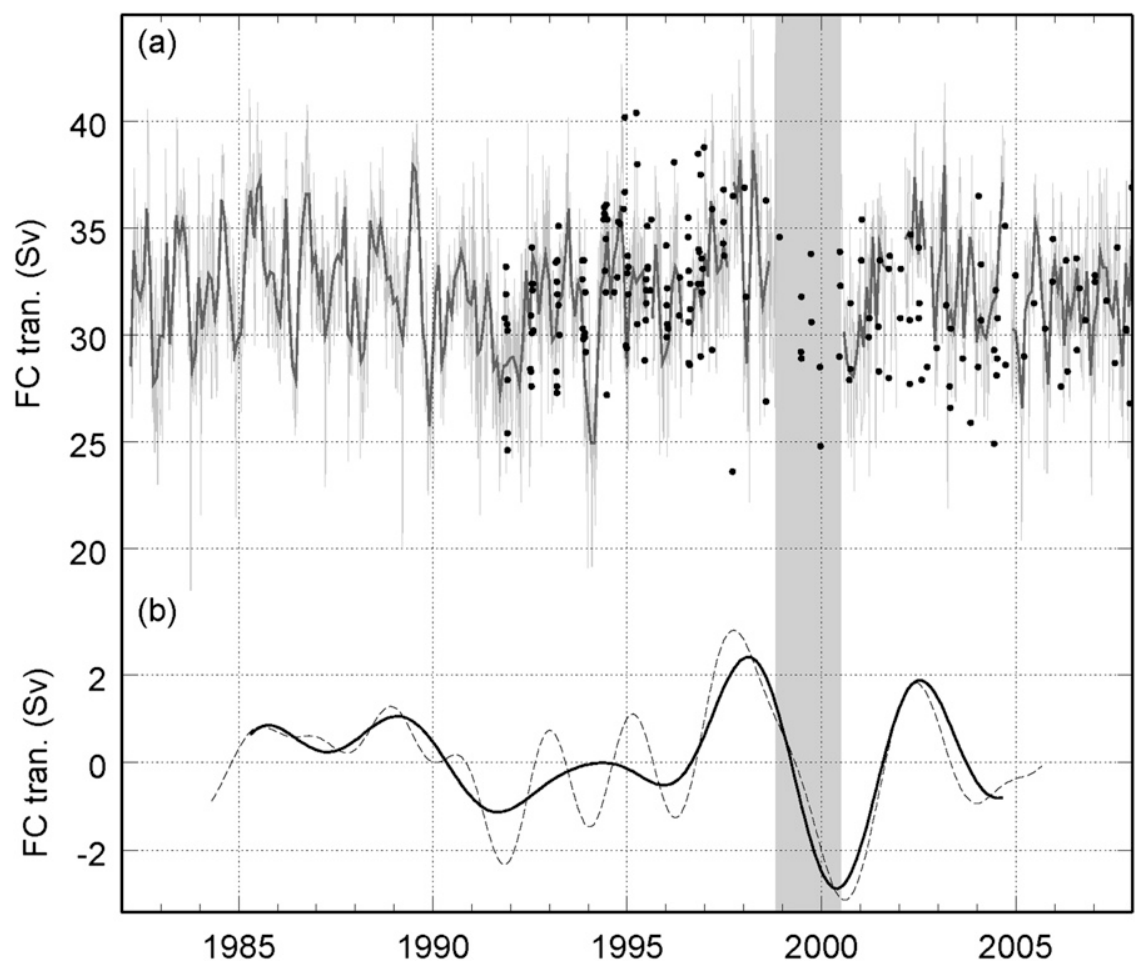

FIG. 1. (a) Monthly estimates (solid line) of FC volume transport computed from daily cable observations (thin line) using the technique described in the text. The black dots correspond to transport estimates obtained using dropsonde sections. (b) Filtered time series of interannual FC transport anomalies. The solid line represents the 3-12-yr (3-12 YBP) bandpass-filtered signal, while the dashed line shows the 2-12-yr (2-12 YBP) bandpass. Sections of the time series subject to filtering edge effects are not shown. The 20-month gap in the cable observations appears in gray, indicating the portion of the time series that has been interpolated, solely to produce a continuous signal for filtering.

have shown that the subtropical gyre wind-driven circulation accounts for about $17 \mathrm{~Sv}$ of the total transport of the Florida Current at $25^{\circ} \mathrm{N}$, with a remaining $13 \mathrm{~Sv}$ identified as water of South Atlantic origin carried by the MOC to the Straits of Florida. Although the validity of Sverdrup balance in the long-term mean gyre dynamics is still a subject of controversy (e.g., Leetmaa et al. 1977; Wunsch and Roemmich 1985; Bryan et al. 1995; Hogg and Johns 1995), there is clear evidence from modeling and observational studies to support an important role for low-frequency WSC changes in the gyre circulation (Sturges and Hong 1995; Sturges et al. 1998; Hong et al. 2000).

Three WSC forcing regions are defined over the $27^{\circ} \mathrm{N}$ latitude band corresponding to the latitude of the telephone cable across the Straits of Florida. This latitude band was chosen according to the physical mechanisms hypothesized to influence the FC transport on interannual scales, as discussed in the introduction. These regions are designated western Northern Atlantic (WNA), central North Atlantic (CNA), and eastern North At- lantic (ENA), as shown from left to right in Fig. 2. Time series of spatially averaged WSC over each region are computed.

Several filter cutoff periods have been evaluated to isolate the low-frequency variability of these WSC time series and to test the sensitivity of the results to the filter periods. Analysis of the spectra of the western and central regions (Fig. 3a) shows a white spectral distribution but with sharp annual and semiannual peaks, consistent with previous results (e.g., Willebrand 1978). Broader plateaus of spectral density are observed at longer periods (lower frequencies) than the annual cycle, accounting for about $10 \%$ of the variance. The significant energy in the interannual portion of the spectrum for the western region is separated from the annual and semiannual peaks by an apparent spectral gap at periods of approximately $2 \mathrm{yr}$, but no such clear separation occurs in the spectra for the central and eastern regions. Signals resulting from lagged composition of the three WSC signals show a relatively redder spectrum, as expected from an integration process, with 


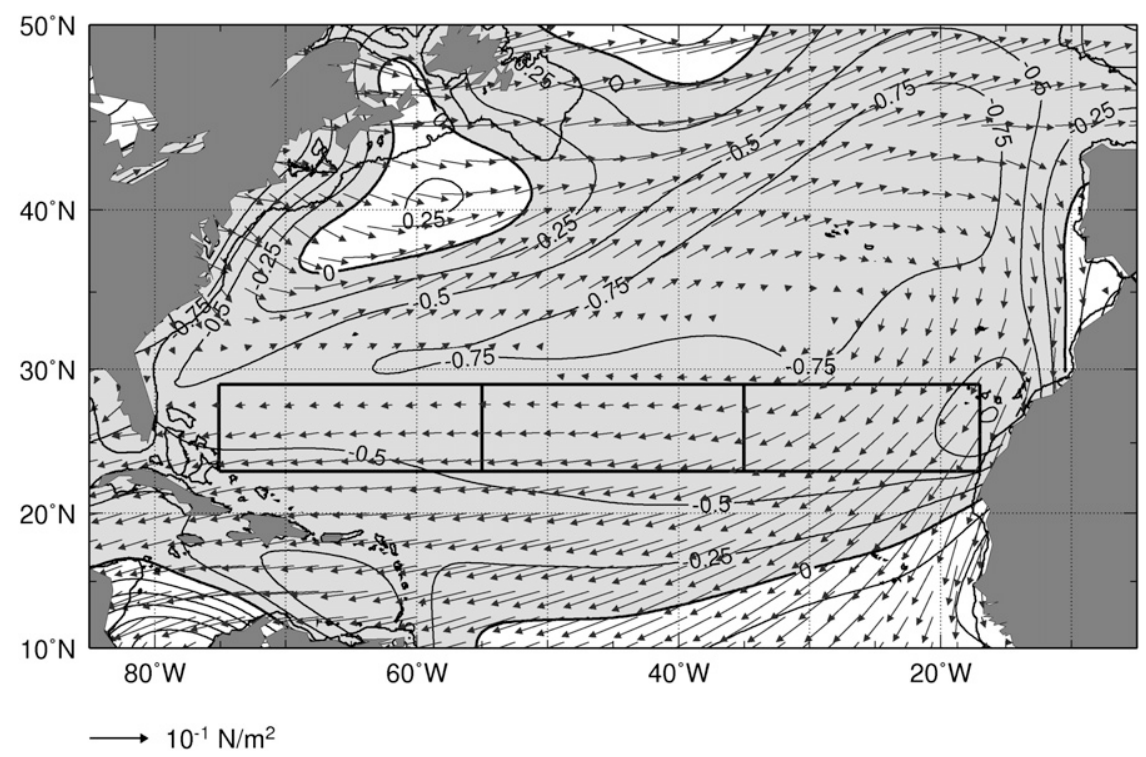

FIG. 2. Climatological mean surface wind stress from the NCEP-NCAR reanalysis project between 1982 and 2007. Arrows show the wind stress field, and the contour map is the vertical component of WSC. The WSC contours are in units of $10^{-7} \mathrm{~Pa} \mathrm{~m}^{-1}$. White (gray) background is for positive (negative) mean WSC. Three regions are outlined across a latitude band centered at $27^{\circ} \mathrm{N}$, corresponding approximately to the Straits of Florida: WNA, CNA, and ENA. WSC forcing over these regions is hypothesized to influence the FC transport on interannual time scales, via baroclinic adjustment. The solid line shown following continental coastlines corresponds to the $200-\mathrm{m}$ isobath.

damped annual and semiannual peaks and clearer cutoffs between 2- and 3-yr periods (figure not shown).

Spectral analysis of the FC time series (Fig. 3b) shows a red spectrum consistent with the multiplicity of physical processes operating on the FC at time scales from seasonal to decadal. Less pronounced annual and semian- nual peaks are also present in comparison with the WSC signals. The interannual portion of the spectrum is separated from the annual peak by a minimum at about the 2-yr period, and the energy in this portion of the spectrum explains about $20 \%$ of the total variance. These results suggest the use of a low-pass cutoff at the
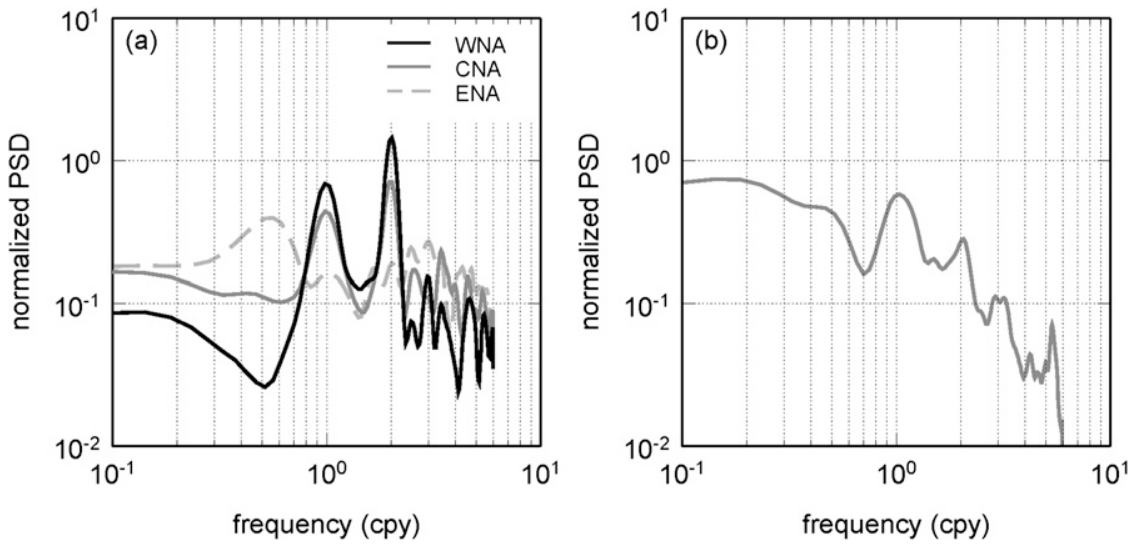

FIG. 3. (a) Spectra of the WSC time series for each forcing region. The lines correspond to regions: solid black is western; solid gray is central; and dashed gray is eastern. (b) Spectrum of the Florida Current transport time series. The time series are normalized to zero mean and unit variance before computing the power spectral density (PSD), resulting in dimensionless values of PSD. The frequency axis is in cycles per year, with $10^{\circ}$ corresponding to the annual frequency. 
3-yr period. Ultimately, this choice is best illustrated by a time-dependent cross-spectral analysis between the composite WSC signal and FC transport like that presented in the results section, where variability at the $3-\mathrm{yr}$ and longer periods show a distinct separation. Additionally, a 12-yr high-pass cutoff has also been applied to the WSC forcing signal to remove decadal- and longerperiod modes, which would not be well resolved by the approximately 25-yr-long FC record.

The NAO index used in this analysis is based on the periodically updated data distributed by the National Oceanic and Atmospheric Administration's Climate Prediction Center (available online at http://www.cpc. noaa.gov/data/teledoc/nao.shtml). This monthly index is derived following the methodology of Barnston and Livezey (1987), based on a rotated principal component analysis that isolates the primary teleconnection patterns of the NAO using year-round data rather than just winter data.

The resulting low-frequency WSC signals for each of the forcing regions (Figs. 4a-4c) all have amplitudes of order $10^{-8} \mathrm{~Pa} \mathrm{~m}^{-1}$, which are about $15 \%$ of the monthly signal amplitude (order of $10^{-7} \mathrm{~Pa} \mathrm{~m}^{-1}$ ) associated with the annual or semiannual peaks. Moreover, a visual correspondence with low-frequency NAO index variability (Fig. 4d) can be observed, especially for the western and central regions. This suggestion of a positive relationship between the NAO and the WSC field over the latitude band of the Straits of Florida is further explored in the next section using a regression analysis of the wind fields and the low-frequency NAO index.

\section{Results}

\section{a. WSC forcing associated with NAO interannual variability}

Since the NAO is a major mode of interannual atmospheric variability over the North Atlantic, we examine low-frequency covariability between the NAO and the wind field over the forcing regions at $27^{\circ} \mathrm{N}$. We linearly regress the monthly wind stress components and their associated curl onto the 3-12 YBP filtered NAO index. Regression coefficients that are significant with $67 \%$ probability are considered. Using this procedure, a pattern of NAO-WSC interannual covariability emerges (Fig. 5), where a high NAO index is associated with positive anomalies in WSC over the western and central portions of the forcing region along $27^{\circ} \mathrm{N}$.

A high NAO index is generally associated with a strengthening of both westerly and trade winds, akin to a strengthening of the mean wind field over the North Atlantic (Fig. 2), which simple intuition might associate with a negative WSC forcing anomaly. Our result, in fact, demonstrates the opposite, showing that a positive WSC anomaly over the latitude band of the Straits of Florida is produced by a band of negative anomalies in the westerlies between about $30^{\circ}$ and $40^{\circ} \mathrm{N}$ (cf. Figs. 5 and 2). These zonal wind anomalies arise from a basinwide anticyclonic atmospheric circulation within the center of action of the NAO near $40^{\circ}-50^{\circ} \mathrm{N}$. The regression further indicates that WSC anomalies associated with low-frequency variability of the NAO, approximately $0.5 \times 10^{-8} \mathrm{~Pa} \mathrm{~m}^{-1}$ in the western and central regions, have the same order of magnitude as the interannual WSC anomalies that are actually observed in the NCEP-NCAR data $\left(10^{-8} \mathrm{~Pa} \mathrm{~m}^{-1}\right.$; Figs. $4 \mathrm{~b}$ and 4c). Additionally, the correlation coefficients associated with the WSC-NAO regressions are found to be significant at the $67 \%$ level over the latitude band hypothesized to influence the Florida Current (Fig. 5b), indicating that a substantial fraction of the interannual variability of the WSC over this region can be linked with the NAO.

The ocean response to the anomalous anticyclonic atmospheric circulation associated with high NAO has been extensively studied, for example, by Eden and Willebrand (2001) and Marshall et al. (2001), focusing on the intergyre dynamics near the subpolar front. This pattern of anomalous easterlies north of the latitude band of the Florida Straits, with positive WSC at about $30^{\circ} \mathrm{N}$, can be recognized in previous studies of the NAO (e.g., Eden and Willebrand 2001; Marshall et al. 2001; Visbeck et al. 2003), yet no links with the Florida Current or with adjustment processes in the subtropical gyre circulation have been proposed. Adjustment of the Sverdrup transport in the North Atlantic subtropical gyre to this positive WSC anomaly should drive a negative anomaly in the FC transport. Thus, the observed WSC-NAO interannual covariability can associate a high NAO index with negative FC transport anomalies, provided that an adjustment process links the gyre-wide WSC forcing with the western boundary current system. Evidence for such a link could, therefore, explain the observed anticorrelation between the NAO index and the cable-derived FC transport time series on interannual time scales (e.g., Baringer and Larsen 2001).

\section{b. Composition of forcing signals based on baroclinic adjustment}

The WSC forcing time series computed for each of the three regions in the latitude band of the Straits of Florida are individually lagged in time and then combined. Composite forcing time series are used to evaluate the potential role of baroclinic adjustment in the lowfrequency adjustment of the North Atlantic subtropical 


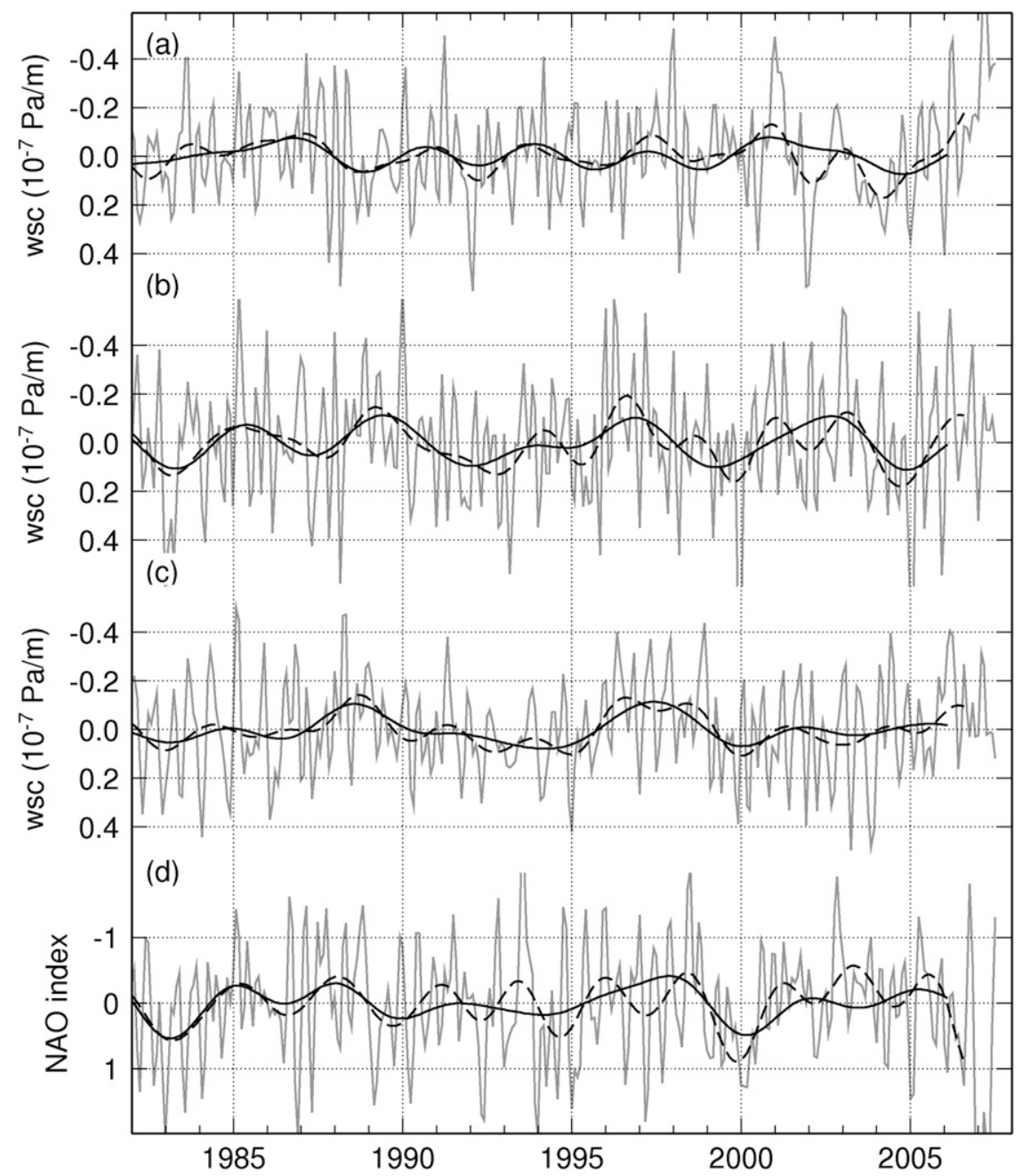

FIG. 4. Time series of WSC from each of the three forcing regions: (a) eastern, (b) central, and (c) western. (d) Time series of NAO index. In each figure, light gray lines are the original unfiltered monthly time series, solid lines are the 3-12 YBP filtered signals, and dashed lines are the 2-12 YBP filtered signals. Note that all four vertical axes are inverted for ease of comparison with the FC signal in Fig. 6.

gyre. Adjustment times associated with the long limit of linear first baroclinic-mode Rossby waves are initially considered. These adjustment times are estimated from the center of each forcing region, based on group propagation speeds obtained by Sturges et al. (1998) using hydrography and standard beta-plane theory. The adjustment times are based on simple linear first baroclinicmode group speeds, derived on a beta plane for an ocean at rest with a flat bottom. Consequently, all potential effects on the adjustment times due to higher baroclinic modes, topography, the full sphericity of the earth's surface, or mean flow are neglected.

The time series of WSC anomaly within each of the three regions are first converted into equivalent Sverdrup transport anomalies and then shifted in time according to the lags specified in Table 1. The Sverdrup integral along $27^{\circ} \mathrm{N}$ (i.e., the gyre-wide Sverdrup transport) is computed as the sum of the lagged Sverdrup transport signals corresponding to the three regions considered. This approximation of the integral as a summation of three spatial averages is valid as a result of the autocorrelation remaining in the filtered signals and the spatial coherence of the low-frequency forcing. For the Sverdrup scaling, we choose a planetary vorticity gradient $\beta=2 \times 10^{-11} \mathrm{~m}^{-1} \mathrm{~s}^{-1}$ corresponding to $27^{\circ} \mathrm{N}$, a seawater reference density $\rho_{0}=10^{3} \mathrm{~kg} \mathrm{~m}^{-3}$, and a zonal extent for each forcing region (Fig. 2) of $L=2 \times$ $10^{6} \mathrm{~m}$. According to the Sverdrup balance (Sverdrup 1947), the volume transport associated with a WSC anomaly of $10^{-8} \mathrm{~Pa} \mathrm{~m}^{-1}$ is 

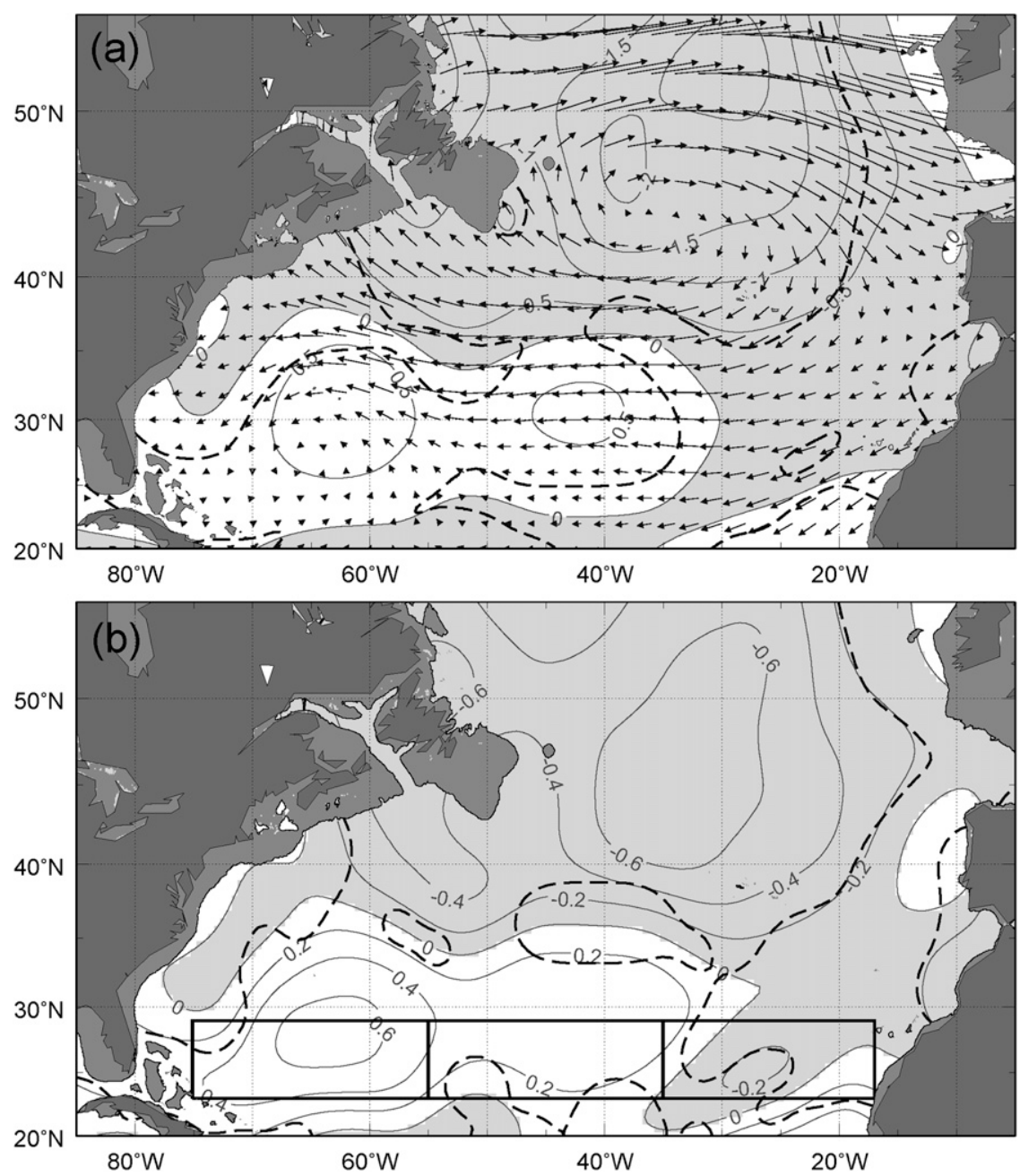

FIG. 5. (a) Wind stress (arrows) and WSC (contours), resulting from a regression of the NCEP-NCAR reanalysis onto a 3-12 YBP filtered time series of the NAO index. The WSC contours are in units of 10-8 $\mathrm{Pa} \mathrm{m}^{-1}$. White (gray) background shows areas of positive (negative) regressed WSC anomaly. A heavy dashed contour outlines areas where the NAO-WSC regression is distinct from the null hypothesis (Student's $t$ test) with $67 \%$ confidence. Note that this area encompasses much of the center of action of the NAO and the entire western and central portions of the $27^{\circ} \mathrm{N}$ latitude band. (b) Correlation coefficient corresponding to the regression results shown in (a). The dashed contour outlines areas where the NAO index-WSC coherence is distinct from the null hypothesis (chi squared).

transport $\sim \frac{(\text { WSC }) L}{\rho_{0} \beta} \cong \frac{\left(10^{-8} \mathrm{~kg} \mathrm{~m}^{-2} \mathrm{~s}^{-2}\right)\left(2 \times 10^{6} \mathrm{~m}\right)}{\left(10^{3} \mathrm{~kg} \mathrm{~m}^{-3}\right)\left(2 \times 10^{-11} \mathrm{~m}^{-1} \mathrm{~s}^{-1}\right)}=10^{6} \mathrm{~m}^{3} \mathrm{~s}^{-1} \mathrm{deg} 1 \mathrm{~Sv}$.

The amplitude of the resulting transport signal is between 2 and $3 \mathrm{~Sv}$ (Figs. 6b and 6c), consistent with observed interannual anomalies in FC transport of $3 \mathrm{~Sv}$ or less, as shown by the 3-12 YBP filtered time series (Figs. 1b or (6a) and as found by Baringer and Larsen
(2001). Note that the signals have opposite signs, since northward anomalies in interior Sverdrup transport lead to southward anomalies in FC transport. Thus, the observed magnitude of interannual WSC anomalies over this latitude band would be sufficient to explain 
TABLE 1. Wave group speeds and hypothetical adjustment times for changes in WSC over each of the three WSC forcing regions corresponding to the $27^{\circ} \mathrm{N}$ latitude band, computed using hydrographic observations and standard beta-plane theory by Sturges et al. (1998).

\begin{tabular}{lccccc}
\hline \hline Region & Lat $\left({ }^{\circ} \mathrm{N}\right)$ & Lon $\left({ }^{\circ} \mathrm{W}\right)$ & Adjustment speed $c_{g}\left(\mathrm{~cm} \mathrm{~s}^{-1}\right)$ & $\begin{array}{c}\text { Mean distance to Straits } \\
\text { of Florida } d(\mathrm{~km})\end{array}$ & $\begin{array}{c}\text { Adjustment time } d c_{g}{ }^{-1} \\
(\mathrm{months})\end{array}$ \\
\hline WNA & $23^{\circ}-29^{\circ}$ & $75^{\circ}-55^{\circ}$ & 4 & 1400 & 13 \\
CNA & $23^{\circ}-29^{\circ}$ & $55^{\circ}-35^{\circ}$ & 3.8 & 3500 & 35 \\
ENA & $23^{\circ}-29^{\circ}$ & $35^{\circ}-15^{\circ}$ & 3.5 & 5200 & 55 \\
\hline
\end{tabular}

observed interannual FC transport anomalies, assuming the two signals are found to be coherent. Some degree of correspondence can be observed between the composite forcing signal (Fig. 6c) and the FC signal (Fig. 6a). However, the composite forcing signal has the appearance of leading the FC fluctuations, even though it has been lagged using linear Rossby wave group speeds. Alternatively, when adjustment times of just $40 \%$ (hereinafter $0.4 \mathrm{X}$ ) of the standard theory are used (Fig. 6b), the composite WSC-driven signal is not only more clearly in phase with FC transport but also appears to be in phase with the NAO signal (Fig. 6d). The correlation coefficient $r$ between the 0.4X-adjusted WSC forcing and the $3-12$ YBP signals of the FC and NAO is -0.72 and 0.69 , respectively, and is -0.71 between the $3-12$ YBP FC and NAO signals (These correlations exclude the 20-month gap in the FC time series, as do all statistical results in this study). Thus, using the faster adjustment times, while implying propagation speeds about twice as fast as classical beta-plane theory, leads to a stronger coherence and increased consistency with the observed NAO-FC relationship. The sensitivity of the coherence and scaling between the WSC forcing and FC transport signals to different assumed adjustment times is explored more carefully in section 3c.

The spatial distribution of the apparent gyre adjustment times can be further investigated by estimating the lags corresponding to the peak coherence (maximum negative regression slope) between interannual WSC forcing variability and FC transport for each $\sim 2^{\circ} \times 2^{\circ}$ grid point in the NCEP-NCAR dataset (Fig. 7b). The western and central regions show the highest peak regression values, while the optimal lags (Fig. 7a) show an increase toward the east in the subtropical North Atlantic, consistent with a westward-propagating adjustment process, such as planetary waves. Again, these adjustment times imply Rossby wave energy propagating with speeds ranging between 2 and 3 times the theoretical values.

In the CNA and WNA regions in Fig. 7b, the estimated lag times imply much faster Rossby wave propagation compared to the 13- and 35-month theoretical adjustment times for these regions given in Table 1 . Conversely, a portion of the ENA region shows implied adjustment times longer than 35 months, more consis- tent with the 55-month lag given for this region in Table 1. Finally, the mean correlation coefficient for each forcing region (Fig. 8) shows that the western and central forcing regions are more coherent $(r>0.6)$ with the FC time series compared with the eastern region $(r<$ $0.4)$. The estimated lag times for these optimal correlation coefficients are $6 \pm 4$ months for the western region, $7 \pm 5$ months for the central region, and $20 \pm 9$ months for the eastern region.

\section{c. Regression of WSC and FC transport interannual variability}

When the standard adjustment times are used (Figs. 6a and $6 \mathrm{c}$ ), the magnitude of the signals' coherence is -0.2 , and the regression coefficient fails the null hypothesis test. Conversely, statistical significance (at 67\% level) is achieved when lag times that are $40 \%$ of the theoretical values are used (Fig. 6b), with correlation coefficients of -0.66 and -0.72 for the $2-12$ - and the $3-12$ YBP filtered signals, respectively. To explore the coherence between the FC and WSC signals over a range of possible adjustment lags, multipliers from -0.5 to 1.5 times the theoretical beta-plane adjustment times are considered, and the sensitivity of the FC response to this one-dimensional parameter (lag multiplier) is examined.

Figure 9 summarize the sensitivity of the FC-WSC linear regression to both the assumed adjustment lag times and the bandpass filtering applied. The regression coefficient corresponds to the slope (or gain) of the least squares best-fit line between the filtered time series of lagged Sverdrup transport forced by the WSC and the FC transport. A regression coefficient of 1.0 would indicate that the low-frequency variability in Sverdrup transport and observed FC transport are consistent, while a high-correlation coefficient simply indicates a high coherence between the signals, without reference to their scaling. The time series are subsampled to reflect a reduction in effective degrees of freedom (DOF) consistent with 2- and 3-yr integral time scales identified in the autocorrelation function of the regression residuals for each cutoff band. The resulting equivalent DOFs for the two cutoff periods are 11 and 7, respectively, after edge effects are removed. 


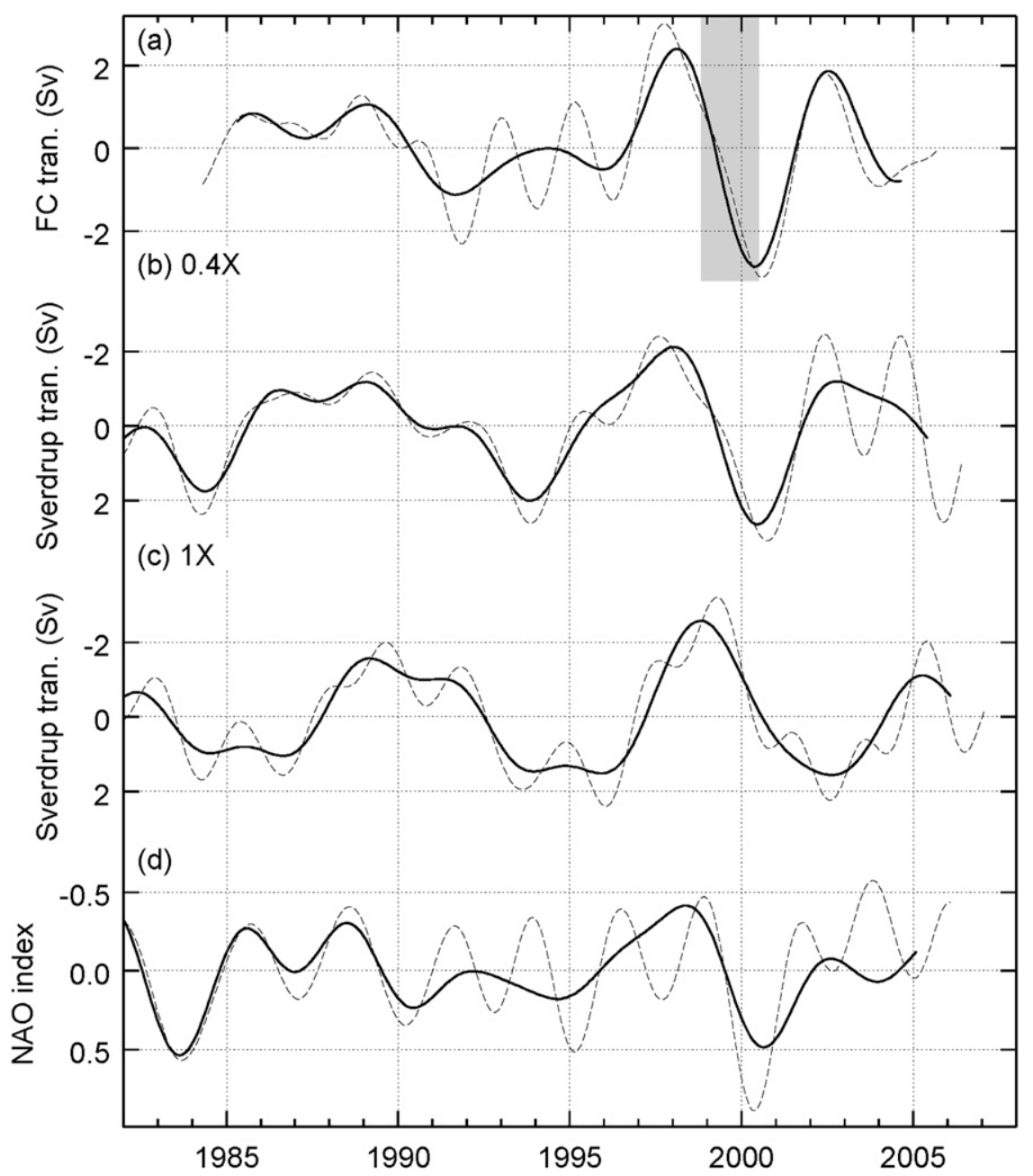

FIG. 6. (a) Filtered time series of FC transport interannual anomalies. The 20-month gap in the cable observations is highlighted in gray to indicate the portion of the time series that has been interpolated for filtering purposes only. (a)-(d) Solid (dashed) line represents the 3-12-yr (2-12-yr YBP) bandpass-filtered signal. (b) Time series of WSC-driven Sverdrup transport anomaly over the latitude band centered at $27^{\circ} \mathrm{N}$ in the North Atlantic. The signal is composed from the three forcing regions using adjustment times $40 \%$ of those predicted by standard theory. The vertical axis in this and all remaining plots of this figure is inverted to facilitate visual comparison with FC transport in (a). (c) A composite forcing signal like that shown in (b) but using fully $100 \%$ of the adjustment times predicted by linear theory. (d) Time series of NAO index. The NAO signal is advanced 6 months in time so that the anticorrelation with the FC signal is maximal $(r=0.76)$. Sections of all time series that were subject to edge effects from signal filtering are not shown.

Despite the relatively low number of DOFs, the correlation and regression coefficients can be estimated with $67 \%$ confidence for those lags at which the coherence is greatest [Fig. 9, solid (dashed) lines indicate coefficients that are (are not) statistically significant]. Note that the correlation and regression coefficients corresponding to the theoretical lags (i.e., a 1.0 lag multiplier) fail the null hypothesis test.

A broadening of the peak correlation arises from autocorrelation added to the WSC transport time series by the filtering process, with the $2-12$ YBP signal showing a narrower correlation peak and stronger statistical confidence. Focusing on the 3-12 YBP filtering (the heavier plot line in Figs. 9a and 9b), we find peaks in the covariability between the filtered WSC signal and the FC signal at lag multipliers between 0.1 and 0.5 of the theoretical adjustment time. Note that the $67 \%$ confidence interval shifts from $[0.0,0.6]$ for the 3-12 YBP time series to $[0.3,0.5]$ for the $2-12$ YBP time series. When the same analysis is performed on the bias $(y$ 

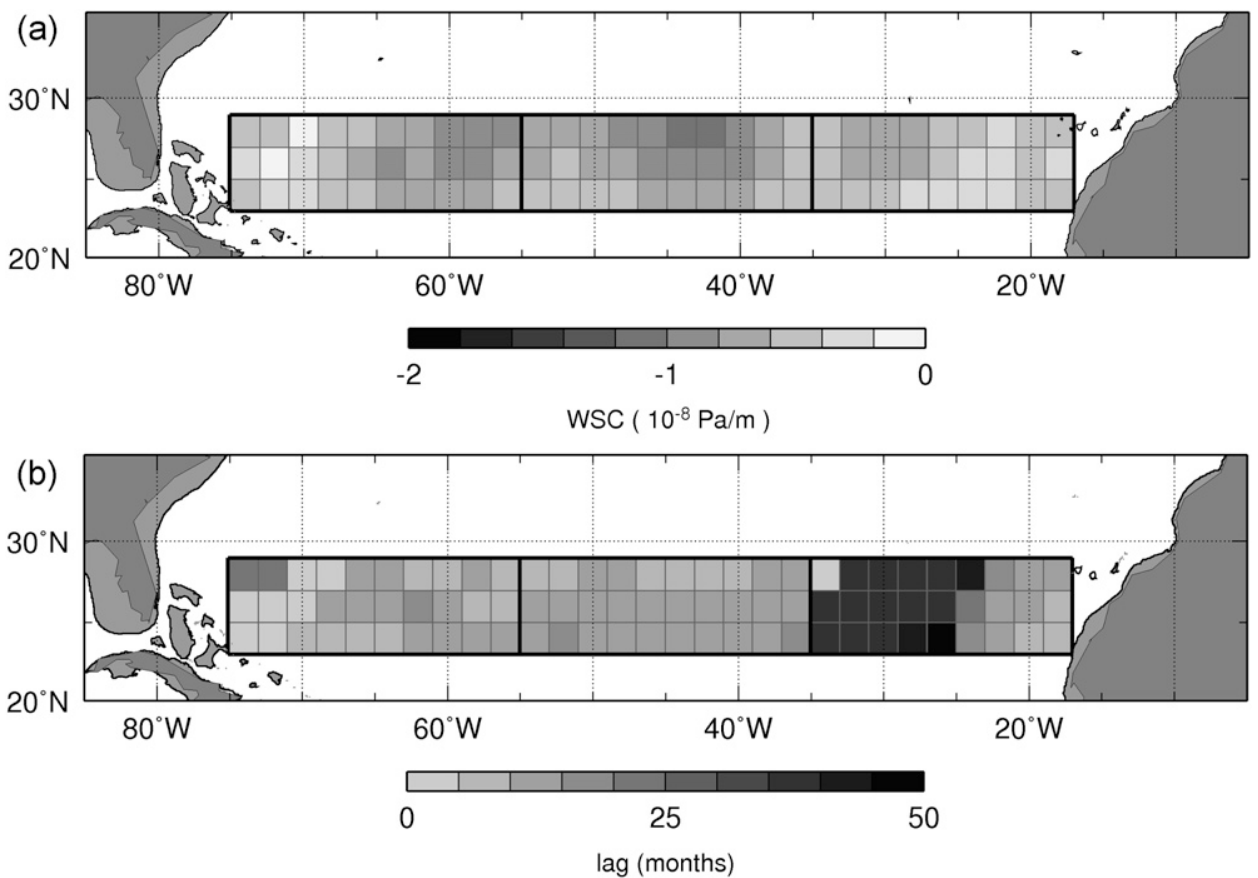

FIG. 7. (a) Map of peak negative regression coefficients, at which the lagged WSC field projects onto the 3-12-yr (3-12 YBP) bandpass-filtered FC transport with greatest negative slope. The linear regressions are computed for each $\sim 2^{\circ} \times 2^{\circ}$ grid cell of the NCEP-NCAR reanalysis, throughout the three forcing regions centered on the $27^{\circ} \mathrm{N}$ band, for the period between 1982 and 2007. (b) Map of lag times in months at which the WSC field projects onto the 3-12 YBP filtered FC transport with greatest negative slope. These lags correspond to the peak regression coefficients shown in (a).

intercept) for each linear regression, no statistically significant values are obtained for the entire multiplier range (not shown). Although the confidence interval for adjustment times in the 3-12 YBP case includes zero, the fact that the peak correlations for both cases occurs between $0.0 \mathrm{X}$ and 1.0X strongly suggests that first-mode baroclinic Rossby waves propagate across the basin with group speeds faster than that dictated by the standard theory.

As described in the discussion section, this conclusion is consistent with a variety of recent observational, modeling, and theoretical studies supporting the existence of faster baroclinic Rossby waves in the oceans. Ultimately, the high coherence between the signals, together with their close scaling to Sverdrup balance, provides substantial evidence for baroclinic adjustment to wind variability as a physical mechanism explaining a significant portion of interannual FC transport variability.

\section{d. Time-dependent cross-spectral analysis}

The regression methodology and results outlined above imply a dynamical link between low-frequency WSC variability and FC transport anomalies at similar frequencies. To explore the robustness of this link over the duration of the record, we use the technique of cross-wavelet transform (XWT; Grinsted et al. 2004) to estimate the time-dependent magnitude and phase of WSC-FC covariability at the range of frequencies resolved by the available record. Unlike traditional crossspectral analysis, XWTs can capture variations in coherence with time. An XWT is shown in Fig. 10 between the monthly FC anomaly (with gaps in the record filled as described in section 2a) and the composite monthly WSC anomaly corresponding to adjustment times $0.4 \mathrm{X}$ of those of classical theory. This XWT shows both the phase and the shared spectral power between changes in WSC forcing (leading signal) and the FC transport (following signal). Darker regions of the graph indicate times (abscissa) and signal periods (ordinate) at which the FC and WSC show the highest common power. A "cone of influence" corresponds to the regions outside the dashed line; this region indicates those times and frequencies that may be subject to aliasing as a result of edge effects.

The XWT analysis clearly shows a strong 3-yr and longer-period coherence between the transport and WSC forcing time series, which seems to make its first appearance during the 1990s. Arrows in this diagram indicate the phase angle at which the signals have the greatest shared power; thus, the arrows pointing from 


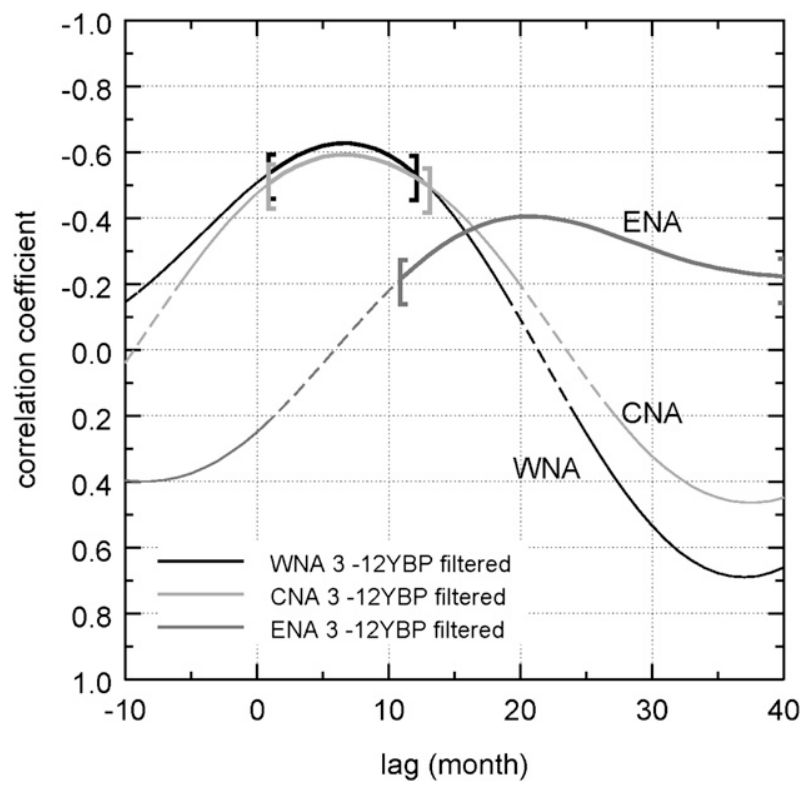

FIG. 8. Correlation coefficient between the 3-12-yr bandpassfiltered (3-12 YBP) FC transport time series and the 3-12 YBP filtered WSC time series corresponding to each forcing region, using a range of lag times in months. Correlation coefficients that are statistically significant at the $67 \%$ confidence level are connected by solid lines; dashed lines connect correlations that lack statistical significance. In addition, lags at which the low-frequency WSC-FC correlation is statistically indistinguishable from that of the peak with $67 \%$ confidence are bounded by square brackets, providing an estimate of the statistical significance of the peak lags.

right to left in the central dark-gray zone indicate anticorrelation. The heavy line indicates areas where the cross-spectral power shown is distinct from the null hypothesis with $67 \%$ or greater confidence. In this type of analysis, the null hypothesis is that both processes are red noise, in this case univariate lag-1 autoregressive processes (AR1).

Anticorrelated variability is also observed at periods of two years during much of the record. This covariability has maximum power in 1994-98, when the coherence between the forcing and transport signals was relatively weak (cf. Figs. $6 a$ and $6 \mathrm{~b}$ ). This coincides with a part of the FC transport record when 2-yr variability appears to have had its greatest relative power but where the WSC signal does not show a particularly strong biennial periodicity. Note that some of the highest interannual variability overlaps the period 1998-2000, during which a 20-month-long gap in the cable record had to be filled. This is a potential weakness of the analysis. However, as shown in Fig. 9, the correlation between the 3-12 YBP time series remains significant when the data from the filled gap is excluded from the analysis. At periods longer than eight years, the transport record is simply too short to analyze. Analysis of longer time series records would be necessary to confirm the apparent time dependence of coherences at these interannual frequencies.

\section{Discussion}

\section{a. Baroclinic adjustment-Rossby wave theory and recent observations}

Using data from the Ocean Topography Experiment (TOPEX)/Poseidon (T/P) satellite mission, CS96 showed that in extratropical regions (outside $10^{\circ} \mathrm{S}-10^{\circ} \mathrm{N}$ ), westward-propagating patterns in sea surface height anomalies (SHAs) - which they characterized as the signature of first-mode baroclinic Rossby wavespropagate faster than predicted by the standard theory assuming a beta plane, no mean background flow, and a flat bottom. The discrepancy between the observed phase speeds and the theoretical values increases with latitude from a factor of 1.5 times faster in the tropics up to 4 times faster in the subpolar oceans. Most of their estimates in the subtropics correspond to the Pacific Ocean, where the amplification factor is approximately 2 at about $30^{\circ} \mathrm{N}$. This value is within the estimated confidence intervals of the lag multipliers of peak coherence shown in Fig. 9.

Subsequent theories motivated by CS96 support the idea that linear theory may be a lower bound for planetary wave propagation speeds. These theories attribute increased phase speeds to a diverse number of factors, such as the effect of the baroclinic mean circulation on potential vorticity gradients (Killworth et al. 1997; Killworth and Blundell 2005), interaction of baroclinic mode waves with topography (Tailleux and McWilliams 2000, 2001), the effect of baroclinic instability (Isachsen et al. 2007), coupling with the atmosphere (White et al, 1998), and the inclusion of full latitude dependence for the Coriolis frequency in the equations of motion on a sphere (Paldor et al. 2007). Dispersion relationships computed numerically by Paldor et al. (2007), based on the shallow-water equations on a sphere, predict planetary waves with a phase speed amplification factor that increases with latitude, consistent with the results of CS96. Killworth and Blundell (2005) used hydrographic observations to estimate the effect of baroclinicity on the potential vorticity gradient. They estimate zonally averaged group speeds for long-limit westward-propagating Rossby waves between 5 and $10 \mathrm{~cm} \mathrm{~s}^{-1}$ at about $30^{\circ} \mathrm{N}$, which are consistent with the lag multipliers shown in Fig. 9. Note that our estimates of adjustment speeds (group speeds) can be compared with the phase speeds estimated by previous studies because we are discussing Rossby waves in the long wave limit. 

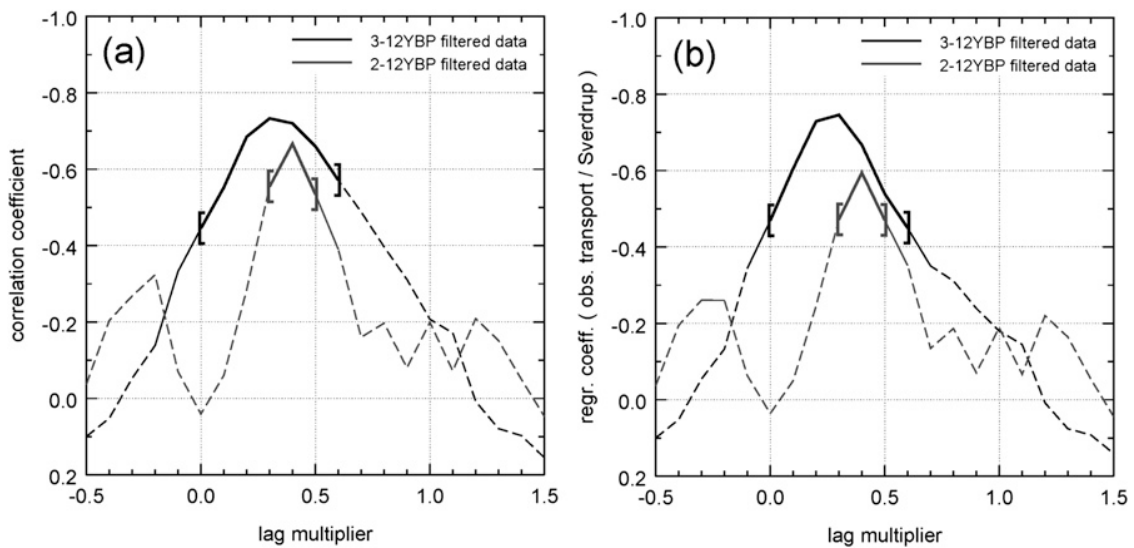

FIG. 9. (a) Correlation and (b) regression coefficients between the FC transport time series and the integrated WSC-driven Sverdrup signals (refer to section 3b). In both diagrams, each point on the abscissa is a multiplier of the standard adjustment times in Table 1. The ordinate shows (a) or (b) between the FC transport and the WSC-driven Sverdrup signal at that lag multiplier. Both diagrams show lag regression curves calculated using bandpass-filtered time series with low-pass filter cutoffs of 24 (2-12) and 36 months (3-12 YBP). Correlation and regression coefficients that are distinct from the null hypothesis with $67 \%$ probability are plotted as solid lines; dashed lines represent coefficients that lack statistical significance. In addition, the ranges of lag multipliers at which the regression coefficients are undistinguishable from the peak with $67 \%$ probability are bounded by square brackets, which show the statistical confidence of the lag multiplier. The significance or lack thereof for the coefficients themselves is represented by the use of solid and dashed line segments, respectively.

Zang and Wunsch (1999, hereafter ZW99) performed a methodologically improved analysis using a longer $\mathrm{T} / \mathrm{P}$ dataset ( $5 \mathrm{yr}$ as opposed to $2 \mathrm{yr}$ by CS96) and found westward-propagating SHA patterns with phase speeds that are indistinguishable from those predicted by the simplest theory for free linear flat-bottom first-mode baroclinic Rossby waves in the long wave limit. Polito and Liu (2003, hereafter PL03) report a conclusion similar to ZW99 based on analysis of a longer (19932000), global T/P dataset using a different methodology. Their zonal averages of phase speed propagation estimated for each basin separately, for planetary waves with periods up to 24 months, suggest no more than a $25 \%$ high bias in $\mathrm{T} / \mathrm{P}$-derived phase speeds compared with linear theory.

The observational analyses of ZW99 and PL03 suggest phase-speed amplification factors closer to 1 , quite distinct from the factor of approximately 2 to 3 , implied by the signal coherences found in our study (section $3 \mathrm{c}$ ). However, the results of ZW99 are representative of only one latitude band in the Pacific Ocean (their areas 3 and 4 , between $18^{\circ}$ and $22^{\circ} \mathrm{N}$ ), while the PL03 results are zonal averages. Moreover, there is observational and theoretical evidence for zonal variations in adjustment times. The analysis of T/P data by Schlax and Chelton (1994) shows an increase in wave amplitude and westward speed caused by interaction with major topographic features, for example, in the North Atlantic, the phase speed of baroclinic Rossby waves appears to change abruptly over the Mid-Atlantic Ridge. Furthermore, Tailleux and McWilliams (2000) demonstrate that in a 2-layer beta-plane model, steep topography enhances the phase of Rossby waves by a factor of $\mathrm{H} / \mathrm{H}_{2}$, where $H$ is total ocean depth, and $H_{2}$ is the depth of the deeper layer. According to these studies, the effect of topography may explain the enhancement of phase speed west from the mid-Atlantic observed in the T/P data and could also explain, at least qualitatively, the spatial distribution of adjustment times identified in our study (Fig. 7b). Considering the unsettled nature of these questions, the signal coherences found in our study should not be ruled out as evidence of real adjustment processes.

\section{b. Other mechanisms influencing FC interannual variability}

Other wind forcing mechanisms influencing the FC variability on shorter time scales, such as those found to drive the seasonal cycle, were considered because they can remain operative on longer time scales. For instance, observations of local wind stress forcing, and topographic wind stress forcing over the western continental slope of the North Atlantic were analyzed consistent with the model studies of Anderson and Corry (1985a,b), Fanning et al. (1994), and Greatbatch et al. (1995). Following the same methodology used to test the baroclinic adjustment hypothesis, coherence is 


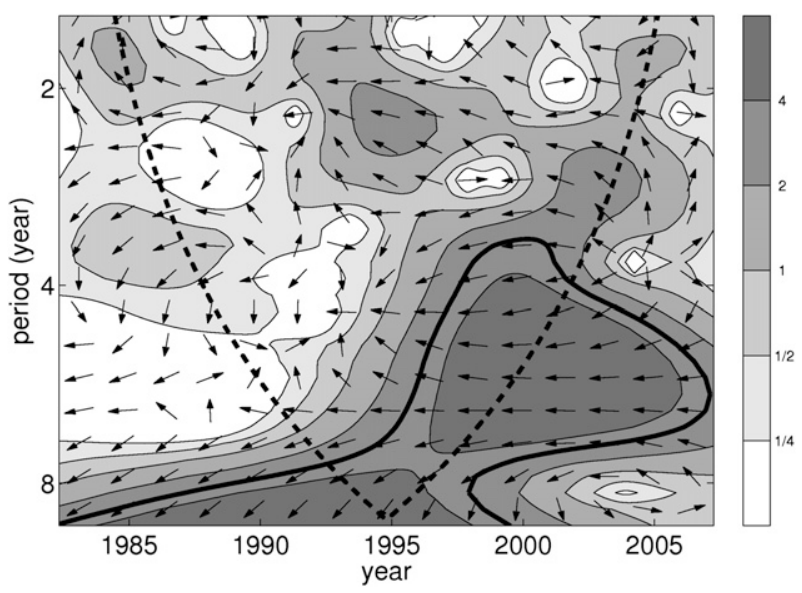

FIG. 10. XWT between the monthly time series of FC cable data and the monthly WSC forcing signal combined using adjustment times $40 \%$ of those predicted by linear theory (Table 1 ). The region outside the dashed line corresponds to those times and frequencies that may be subject to aliasing as a result of edge effects. The solid line delimits those times and frequencies when the shared power is significant with respect to null hypothesis (i.e., both signals are AR 1 processes) with $67 \%$ confidence. The grayscale shows cross-wavelet power on an arbitrary scale in which darker colors indicate higher power. Arrows indicate the phase angle of greatest coherence; thus, arrows pointing from right to left indicate anticorrelation.

identified between the cable-derived FC transport and both local and remote wind stress forcing along regions of the western continental slope of the North Atlantic Ocean. However, the coherence is of relatively less importance than that found for the WSC forcing $(r<$ $0.5)$. Furthermore, the adjustment times implied are on the order of one year, a result that is more difficult to reconcile with the fast adjustment times expected from the coastal trapped waves involved in this type of response. For this reason, we do not consider coastal wind stress forcing in detail in this paper.

\section{Summary and conclusions}

The main finding of this paper is that interannual variability of reanalysis-derived wind stress curl (WSC) over the latitude band of the Straits of Florida explains about half of the interannual variance $\left(r^{2}=0.5\right)$ of the cable-derived FC transport with $67 \%$ statistical significance. Our linear regression results summarized in Fig. 9 indicate both correlation and regression coefficients of about 0.7 and a regression bias statistically indistinguishable from zero, using a presumed lag equal to $40 \%$ of the theoretical first-mode baroclinic adjustment times. These observed lag times imply adjustment by long-limit baroclinic Rossby waves propagating at group speeds considerably faster than those predicted by classical linear theory assuming a beta plane and flat bottom. This observational estimate is qualitatively consistent with the majority of theoretical and observational studies that have followed the analysis of satellite sea surface height observations by CS96. The faster Rossby waves implied by the lags estimated in our study may be reconciled with the literature if zonal variation in the propagation speeds are considered. The strong contrast in the spatial distribution of observed lags between the western and the eastern basins in the subtropical North Atlantic is suggestive of waves being sped up because of interactions with the Mid-Atlantic Ridge. Killworth and Blundell (2005), Tailleux and McWilliams (2000, 2001), and Paldor et al. (2007) all provide complementary theoretical frameworks that help explain the adjustment times estimated by our regression analysis. However, a consensus Rossby wave theory, not yet available, would be of great value in interpreting results like ours. Nevertheless, based on the significance of the signal coherence, signal scaling relative to Sverdrup balance, and the spatial distribution of the implied lags identified in this study, we conclude that the observed interannual variability of the FC transport can be attributed in large part to baroclinic adjustment of the North Atlantic subtropical gyre to low-frequency changes in wind forcing. Ultimately, longer records of transport estimates are needed to improve the statistical confidence of our results, and a richer theoretical framework is needed to understand the observed physics with more detail.

The amplitude of variability at interannual frequencies shows notable time dependence, in both the spectrum of FC transport and the cross-spectrum between FC transport and WSC forcing over the $27^{\circ} \mathrm{N}$ latitude band. Insufficient data exist from the cable measurement of FC transport considered in this study to analyze either the statistical properties of this time dependence or to determine its possible physical mechanisms from these data. However, this does point to an area of potentially fertile study, using both earlier records of direct observations and proxies such as coastal sea level data, which may reliably extend the available record length of the FC transport time series to allow decadal and longer-period signals to be analyzed within it.

Analysis of the global satellite altimetry dataset, now twice as long as in any of the studies cited above, should shed considerable new light on the zonal variation of propagation speeds of long-limit Rossby waves in the real North Atlantic. Improved estimation of the baroclinic adjustment times in the western subtropical North Atlantic is crucial for the inference relating FC transport variability to WSC on interannual scales. Current efforts 
to predict interannual changes in North Atlantic circulation (Meinen et al. 2007) could benefit from refined understanding of FC-WSC low-frequency variability, such as is outlined in this paper.

As previously mentioned, we find that wind forcing explains $50 \%$ of the interannual variability of the Florida Current. Low-frequency wind stress variations associated with coastal wave phenomena may also play some role in forcing interannual FC variability, but our analysis indicates this is likely to be of secondary importance. In addition, it is unclear how these coastal forcing mechanisms could link NAO and FC low-frequency variability. However, part of the unexplained FC variance could result from MOC variability, since the $\mathrm{FC}$ is a return pathway both for the wind-driven gyre circulation and the Atlantic MOC (Schmitz and Richardson 1991). Characterizing the covariance between interannual variability in wind forcing and FC transport, as we have done in this study, could facilitate the analysis of MOC signals in the total transport time series. Monitoring this component of the Atlantic MOC is of great importance, since it is closely related to the interhemispheric water exchange that supports the northward heat transport of the Atlantic Ocean, a major feature of the global climate.

To conclude, the spatial pattern of NAO-correlated WSC interannual variability indicates that high (low) NAO produces positive (negative) WSC anomalies in the western and central North Atlantic between $20^{\circ}$ and $30^{\circ} \mathrm{N}$, that when scaled according to the Sverdrup balance are sufficient to drive much of the observed interannual variability in the FC transport. This feature of the low-frequency NAO-WSC pattern has not been previously highlighted, owing perhaps to the much larger anticyclonic WSC signal located further north and to the idea that this may be the dominant driver of the observed FC-NAO correlation (e.g., Baringer and Larsen 2001) appears to be new. Our suggestion, therefore, that baroclinic adjustment is operative, at the time scales investigated in this study, provides a physically plausible mechanism to explain the FC-NAO anticorrelation identified by previous studies. Further analysis with longer FC transport records could both confirm the physicality of this mechanism with more certainty and allow exploration of its role in explaining FC variability at decadal and longer time scales.

Acknowledgments. NCEP-NCAR reanalysis data are provided by the NOAA/OAR/ESRL PSD (available online at http://www.cdc.noaa.gov/cdc/data.ncep.reanalysis. derived.surfaceflux.html). The Florida Current cable and section data on NOAA's Atlantic Oceanographic and Meteorological Laboratory (AOML) Web site (available online at http://www.aoml.noaa.gov/phod/ floridacurrent) and are funded by the NOAA Office of Climate Observations. The NAO index is provided by NOAA/CPC at their Web site (available on online at http://www.cpc.noaa.gov/data/teledoc/nao.shtml).

This research was carried out in part under the auspices of CIMAS, a join institute of the University of Miami and NOAA (Cooperative Agreement NA17RJ1226). PD and LW were supported by NOAA/AOML and CIMAS, WJ was supported by NSF Grant OCE-0241438, and $\mathrm{CM}$ and $\mathrm{MB}$ were supported by the NOAA Western Boundary Time Series project.

We thank Remi Tailleux and Peter Killworth for interesting exchanges on recent Rossby wave theories. Robert Molinari, Sang-Ki Lee, Tony Sturges, and an anonymous reviewer provided helpful comments that improved an earlier version of the manuscript. Amy Clement provided a number of suggestions that helped improve the statistical analysis of the results. The initial research for this paper was conducted as part of a graduate course at the University of Miami, during which time a classmate, Corinne Hartin, provided both insight and encouragement. Cross-wavelet and wavelet coherence software was provided by A. Grinsted. All of the figures in this paper using maps or time series were created using the free GMT software package.

\section{REFERENCES}

Anderson, D. L. T., and A. E. Gill, 1975: Spin-up of a stratified ocean with applications to upwelling. Deep-Sea Res., 22, 583-596.

, and R. A. Corry, 1985a: Seasonal transport variations in the Florida Straits: A model study. J. Phys. Oceanogr., 15, 773-786. , and $-1985 \mathrm{~b}$ : Ocean response to low frequency wind forcing with application to the seasonal variation in the Florida Straits-Gulf Stream transport. Prog. Oceanogr., 14, 7-40.

_, K. Bryan, A. E. Gill, and R. C. Pacanowski, 1979: The transient response of the North Atlantic: Some model studies. J. Geophys. Res., 84, 4795-4815.

Baringer, M. O., and J. C. Larsen, 2001: Sixteen years of Florida Current transport at $27^{\circ}$ N. Geophys. Res. Lett., 28, 3179-3182.

Barnier, B., 1988: A numerical study on the influence of the midAtlantic Ridge on nonlinear first-mode baroclinic Rossby waves generated by seasonal winds. J. Phys. Oceanogr., 18, 417-433.

Barnston, A. G., and R. E. Livezey, 1987: Classification, seasonality and persistence of low-frequency atmospheric circulation patterns. Mon. Wea. Rev., 115, 1083-1126.

Böning, C. W., R. Döscher, and R. G. Budich, 1991: Seasonal transport variation in the western subtropical North Atlantic: Experiments with an eddy-resolving model. J. Phys. Oceanogr., 21, 1271-1289.

Bryan, F. O., C. W. Böning, and W. R. Holland, 1995: On the midlatitude circulation in a high-resolution model of the North Atlantic. J. Phys. Oceanogr., 25, 289-305.

Chelton, D. B., and M. G. Schlax, 1996: Global observations of oceanic Rossby waves. Science, 272, 234-238.

Eden, C., and J. Willebrand, 2001: Mechanism of interannual to decadal variability in the North Atlantic Circulation. J. Climate, 14, 2266-2280. 
Fanning, A. F., R. J. Greatbatch, A. M. Da Silva, and S. Levitus, 1994: Model-calculated seasonal transport variations through the Florida Straits: A comparison using different wind-stress climatologies. J. Phys. Oceanogr., 24, 30-45.

Greatbatch, R. J., Y. Lu, B. deYoung, and J. C. Larsen, 1995: The variation of transport through the Straits of Florida: A barotropic model study. J. Phys. Oceanogr., 25, 2726-2740.

Grinsted, A., J. C. Moore, and S. Jevrejeva, 2004: Application of the cross wavelet transform and wavelet coherence to geophysical time series. Nonlinear Processes Geophys., 11, 561-566.

Hamilton, P., J. C. Larsen, K. D. Leaman, T. N. Lee, and E. Waddell, 2005: Transports through the Straits of Florida. $J$. Phys. Oceanogr., 35, 308-322.

Hogg, N. G., and W. E. Johns, 1995: Western boundary currents. Rev. Geophys., 33, 1311-1334.

Hong, B. G., W. Sturges, and A. J. Clarke, 2000: Sea level on the U.S. East Coast: Decadal variability caused by open ocean wind-curl forcing. J. Phys. Oceanogr., 30, 2088-2098.

Hurrell, J. W., and H. van Loon, 1997: Decadal variations in climate associated with the North Atlantic Oscillation. Climatic Change, 36, 301-326.

Isachsen, P. E., J. H. LaCasce, and J. Pedlosky, 2007: Rossby wave instability and apparent phase speeds in large ocean basins. $J$. Phys. Oceanogr., 37, 1177-1191.

Kalnay, E. M., and Coauthors, 1996: The NCEP/NCAR 40-Year Reanalysis Project. Bull. Amer. Meteor. Soc., 77, 437-471.

Killworth, P. D., and J. R. Blundell, 2005: The dispersion relation for planetary waves in the presence of mean flow and topography. Part II: Two-dimensional examples and global results. J. Phys. Oceanogr., 35, 2110-2133.

—, D. B. Chelton, and R. A. de Szoeke, 1997: The speed of observed and theoretical long extratropical planetary waves. J. Phys. Oceanogr., 27, 1946-1966.

Larsen, J. C., 1992: Transport and heat flux of the Florida Current at $27^{\circ} \mathrm{N}$ derived from cross-stream voltages and profiling data: Theory and observations. Philos. Trans. Roy. Soc. London, A338, 169-236.

- , and T. B. Sanford, 1985: Florida Current volume transports from voltage measurements. Science, 227, 302-304.

Lee, T. N., and E. Williams, 1988: Wind-forced transport fluctuations of the Florida Current. J. Phys. Oceanogr., 18, 937-946.

— F. A. Schott, and R. Zantopp, 1985: Florida Current: Lowfrequency variability as observed with moored current meters during April 1982 to June 1983. Science, 227, 298-302.

Leetmaa, A., P. Niiler, and H. Stommel, 1977: Does the Sverdrup relation account for the mid-Atlantic circulation? J. Mar. Res., 35, $1-10$.

Marshall, J., H. Johnson, and J. Goodman, 2001: A study of the interaction of the North Atlantic Oscillation with ocean circulation. J. Climate, 14, 1399-1421.

Mayer, D. A., and J. C. Larsen, 1986: Tidal transport in the Florida Current and its relationship to tidal heights and cable voltages. J. Phys. Oceanogr., 16, 2199-2202.

Meinen, C., S. Garzoli, T. Delworth, and J. Marshall, cited 2007: Atlantic decadal variability: Combining observations and models to investigate predictability. [Available online at http://www. usclivar.org/science_status/AMOC/AOML_DecadalWorkshop Report_Final.pdf.]

Molinari, R. L., W. D. Wilson, and K. Leaman, 1985: Volume and heat transports of the Florida Current: April 1982 through August 1983. Science, 227, 295-297.
Paldor, N., S. Rubin, and A. J. Mariano, 2007: A consistent theory for linear waves of the shallow-water equations on a rotating plane in midlatitudes. J. Phys. Oceanogr., 37, 115-128.

Pedlosky, J., 2000: The transmission and transformation of baroclinic Rossby waves by topography. J. Phys. Oceanogr., 30, 3077-3101.

— barriers. J. Phys. Oceanogr., 29, 2332-2349.

Polito, P. S., and W. T. Liu, 2003: Global characterization of Rossby waves at several spectral bands. J. Geophys. Res., 108, 3018, doi:10.1029/2000JC000607.

Qiu, B., W. Miao, and P. Müller, 1997: Propagation and decay of forced and free baroclinic Rossby waves in off-equatorial oceans. J. Phys. Oceanogr., 27, 2405-2417.

Richardson, W. S., and W. J. Schmitz Jr., 1965: A technique for the direct measurement of transport with application to the straits of Florida. J. Mar. Res., 23, 172-185.

Sanford, T. B., 1982: Temperature transport and motional induction in the Florida Current. J. Mar. Res., 40 (Suppl.), 621-639.

Schlax, M. G., and D. B. Chelton, 1994: Detecting aliased tidal errors in altimeter height measurements. J. Geophys. Res., 99, 12 603-12 612

Schmitz, W. Jr., and P. Richardson, 1991: On the sources of the Florida Current. Deep-Sea Res., 38 (Suppl.), 379-409.

Schott, F. A., and R. Zantopp, 1985: Florida Current: Seasonal and interannual variability. Science, 227, 308-311.

Stommel, H., 1948: The theory of the electric field induced in deep ocean currents. J. Mar. Res., 7, 386-392.

Sturges, W., and B. G. Hong, 1995: Wind forcing of the Atlantic thermocline along $32^{\circ} \mathrm{N}$ at low frequencies. J. Phys. Oceanogr., 25, 1706-1715.

,$--\ldots$, and A. J. Clarke, 1998: Decadal wind forcing of the North Atlantic subtropical gyre. J. Phys. Oceanogr., 28, 659-668.

Sverdrup, H. U., 1947: Wind-driven currents in a baroclinic ocean, with application to the equatorial currents of the eastern Pacific. Proc. Natl. Acad. Sci. USA, 33, 318-326.

Tailleux, R., and J. C. McWilliams, 2000: Acceleration, creation, and depletion of wind-driven, baroclinic Rossby waves over an ocean ridge. J. Phys. Oceanogr., 30, 2186-2213.

_ - and — 2001: The effect of bottom pressure decoupling on the speed of extratropical, baroclinic Rossby waves. J. Phys. Oceanogr., 31, 1461-1476.

Visbeck, M., E. Chassignet, R. Curry, T. Delworth, B. Dickson, and G. Krahmann, 2003: The ocean's response to North Atlantic Oscillation variability. The North Atlantic Oscillation, Geophys. Monogr., Vol. 34, Amer. Geophys. Union, 113-146.

White, W. B., 1977: Annual forcing of baroclinic long waves in the tropical North Pacific. J. Phys. Oceanogr., 7, 50-61.

_ , Y. Chao, and C. K. Tai, 1998: Coupling of biennial oceanic Rossby waves with the overlying atmosphere in the Pacific basin. J. Phys. Oceanogr., 28, 1236-1251.

Willebrand, J., 1978: Temporal and spatial scales of the wind field over the North Pacific and North Atlantic. J. Phys. Oceanogr. 8, 1080-1094.

Wunsch, C., and D. Roemmich, 1985: Is the North Atlantic in Sverdrup balance? J. Phys. Oceanogr., 15, 1876-1880.

Zang, X. Y., and C. Wunsch, 1999: The observed dispersion relationship for North Pacific Rossby wave motions. J. Phys. Oceanogr., 29, 2183-2190. 